\title{
EXCAVACIONES EN LA MISIÓN SAN ANTONIO DE PADUA, ALTA CALIFORNIA
}

\author{
Por \\ Robert L. Hoover*
}

\begin{abstract}
RESUMEN
La California Polytechnic State University ha realizado estudios arqueológicos en la Misión San Antonio de Padua, ubicada en el condado de Monterrey, Alta California. El potencial arqueológico de este sitio ha permitido disef́ar planes de investigación utilizados en la formación de estudiantes de antropología.

En este artículo se describen detalladamente las características de los edificios y residencias que formaban la misión, así como las actividades domésticas y económicas que se llevaban a cabo en ellos. Como resultado de las excavaciones se pudo observar que las diferentes etapas en la construcción de la misión reflejan los grados de influencia y fusión entre los materiales y técnicas introducidas por los misioneros con formas y funciones indígenas, dando como producto una serie de artefactos que reflejan un sincretismo cultural español-mexicano-indígena.
\end{abstract}

\begin{abstract}
California Polytechnic State University has carried out archeological studies in Mission Antonio de Padua, located in Monterrey County, California. The archeological potential of this site has made it useful in designing research plans for teaching anthropology students.

This article describes in detail the characteristics of the residences and other buildings that make up the mission, as well as the business and domestic activities that took place in each. During excavation, it was possible to observe how the different stages of construction at the mission show the degrees of influence and merging of the materials and techniques introduced by the missionaries, with forms and functions that were a contribution of the native people, producing a series of artifacts that reflect a Spanish-Mexican-Indian cultural syncretism.
\end{abstract}

\section{INTRODUCCIÓN}

En 1979, la California Polytechnic State University fue invitada a iniciar un programa de estudios arqueológicos en la Misión San Antonio de Padua en el sur del condado de Monterrey, Alta California. La Misión San

\footnotetext{
* Profesor de antropología, Social Sciences Department. California Polytechnic State University, San Luis Obispo.
} 
Antonio fue fundada en 1771, siendo la tercera de las 21 misiones costeñas franciscanas de Alta California, ubicada en el territorio de los indios Salina del Norte. Llegó a ser una empresa muy exitosa, dado que fue la primera de su género en la Alta California en atraer una población neófita de más de 1000 nuevos creyentes entre la población indígena, la primera en emplear el uso del tejado de losa; y la primera en construir un sistema extensivo de acueductos para la agricultura irrigada. La población de San Antonio alcanzó un máximo de 1300 neofitos en 1803, antes de, con el tiempo, secularizar y declinar después del año 1834. La mayoría de las otras misiones de la Alta California formaron el núcleo de pueblos posteriores, dejando apenas la iglesia preservada en el centro de la comunidad. Este fenómeno nunca ocurrió en la Misión San Antonio, que permaneci6 en un ambiente rural, preservando bajo tierra, como un gran sitio arqueológico, muchos edificios relacionados con residencias y actividades económicas de la gran comunidad autosuficiente. Es prácticamente ilimitada la cantidad potencial de información económica y tecnológica que se puede obtener de un sitio como éste. De muchas maneras, la historia posterior de la Mision San Antonio y su estado de preservación se asemejan a varias de las misiones de Baja California, como la Misión San Fernando Velicat.

Desde 1976 la investigación arqueologica ha continuado sin interrupción en la Misión San Antonio. Se podría pasar provechosamente varias vidas en este lugar. Varias centenas de estudiantes de los Estados Unidos, México, Canadá y Europa han obtenido aquí instrucción intensiva y comprensiva a nivel universitario en metodología de trabajos, ambos en el campo y en el laboratorio. Los alumnos son expuestos al espectro entero de técnicas arqueológicas, desde el reconocimiento y excavación del sitio hasta el análisis de él. No estimulamos la especialización ni la segmentación de tareas. Cada alumno excava, registra, limpia, cataloga e identifica artefactos de su propia unidad con el método vientre a tumba. Los alumnos también aprenden a apreciar la cultura indígena local y todo aspecto de la vida colonial e historia española. Además se han elaborado planes de investigación para cada área de excavación en la Misión San Antonio de Padua.(Figura 1).

\section{EL DORMITORIO DE NEÓFITOS CASADOS (1976-1978)}

En sus primeros tres años, los trabajos se limitaron a la excavación de cuatro salas en el dormitorio de indígenas neofitos casados. Un análisis arquitectónico reveló que estas salas formaban parte de un ala larga de cubículos rectangulares contiguos. que medían aproximadamente 3.88 por 
4.78 metros en sus dimensiones externas, y construidas conforme planos idénticos. El ala de dormitorios fue construida de bloques de adobe colocados sobre dos filas paralelas de cimientos de adoquines fluviales, montados en zanjas poco profundas. Los cimientos de cantera tenían entre 1 y 1.25 metros de anchura. Cimientos más estrechos, con aproximadamente 0.75 metros de anchura, servían de separación entre las salas contiguas. Las bases de adoquines sobresalían cerca de $12 \mathrm{~cm}$ de la superficie térrea original para prevenir la impregnación de agua y el desplome de la base de los muros de adobe (figura 2).

Cada sala tenía un suelo de adobe, firmemente apisonado y pulido en ciertas áreas por el tráfico pedestre, en el centro contenían un hogar amorfo, representado hoy día por tierra cenicienta suelta y fragmentos de carbon. En el portal de la sala 3, fueron colocados tres ladrillos sobre la base de adoquines para formar una pieza de apoyo elevada y chata. No hubo evidencia concreta para la existencia de ventanas en ninguna de las cuatro salas.

Los patios traseros contenían gran cantidad de huesos de animales, lo que indicó que el área fue utilizada al menos para deshacerse de la basura, durante o después de la ocupación de las salas. Los patios frontales contenían más material óseo, material ceniciento que había sido barrido "de las salas, y varios metates, un indicio de que allí se realizaba la preparación de alimentos. Se registró la existencia de un hogar adoquinado enfrente de la sala 3.

Fue en el cuadrante noroeste de la sala 4 donde se expuso el aspecto más sobresaliente del proyecto. Esa parte de la sala fue pavimentada con ladrillos, lo que nos hace suponer que pudo haber sido ocupada por un individuo de alto rango, sin embargo, no hay evidencia de una utilización especializada. Varios de los ladrillos fueron decorados con diseños hechos por impresión digital —círculos, cruces, y líneas diagonales cruzadas-, reflejando mayormente inspiración en la simbología cristiana. Como parte del trabajo de investigación, se llevó a cabo la remoción íntegra del piso de ladrillos y su instalación en el museo de la misión.

Las salas contenían unos cuantos fragmentos de madera carbonizada, que pueden representar restos de vigas y dinteles utilizados en el edificio. Hay amplia evidencia documental y arqueológica de la existencia de un techo de tejas que desapareció en manos de chirrioneros durante los periodos mexicano y anglosajon. Una cerradura de hierro indica que las sạlas tenían puertas de madera con artefactos de metal (figuras 3 y 4).

Basado en la información recogida del proyecto arqueologico, se hace evidente que las familias de neofitos casados utilizaron mucho más espacio para sus vidas diarias que lo que representan sus viviendas de una sola y pequeña habitación. En primer lugar, muchos adultos pudieron haber 


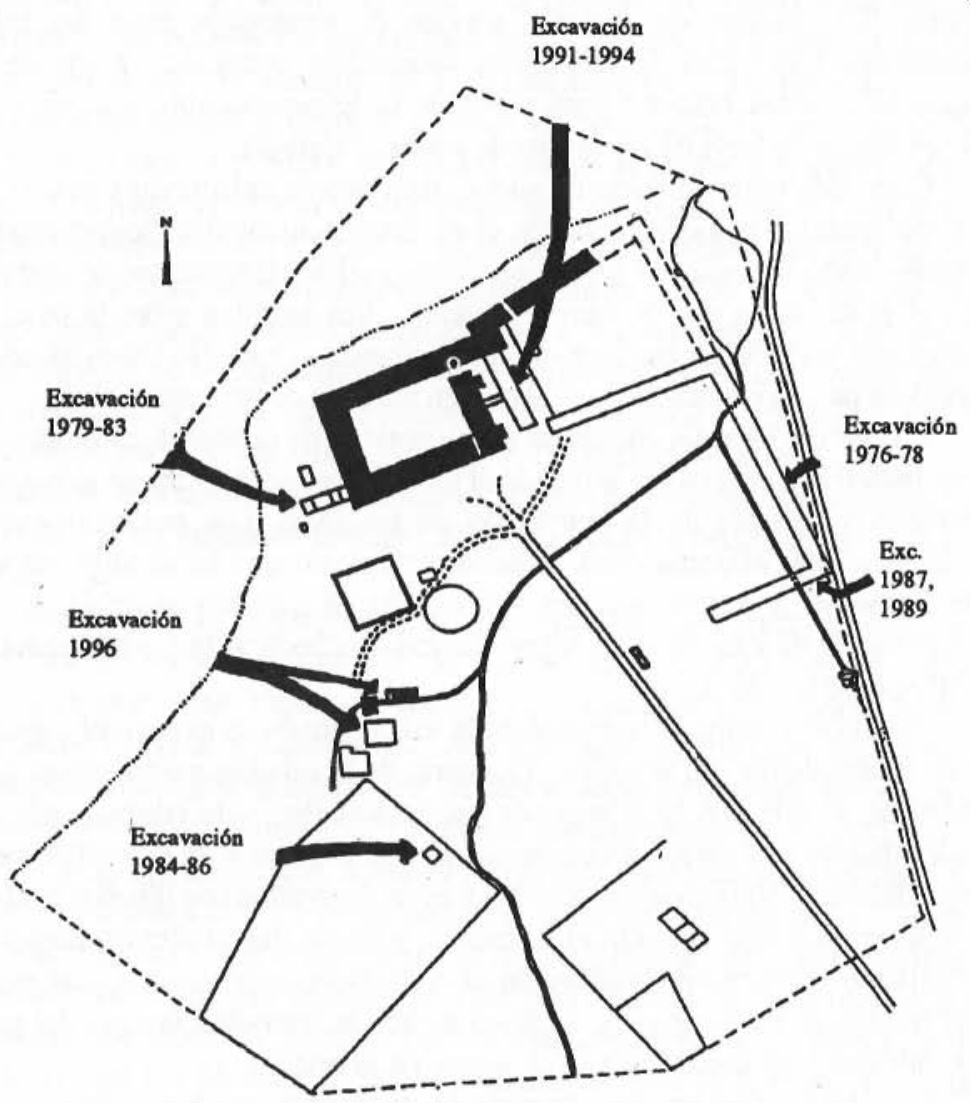

Figura 1. Áreas de excavación. 


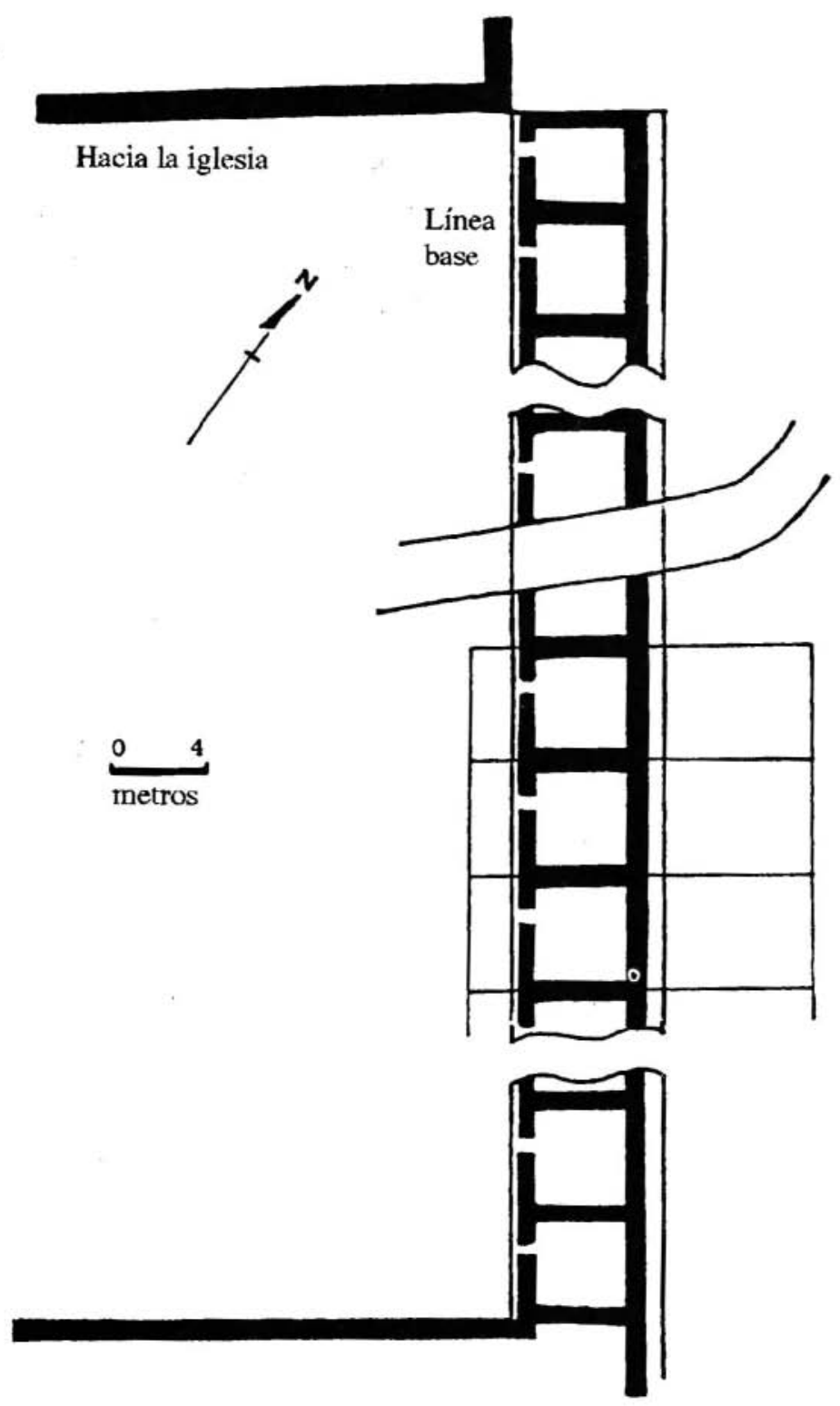

Figura 2. Plano de los dormitorios. 
estado ausentes del hogar durante el día, debido a su ocupación, realizando las faenas propias de una comunidad misional en plena prosperidad. Las piezas eran utilizadas para almacenaje y descanso, mientras los patios frontales servían, durante las estaciones templadas, para cocinar y otras actividades cotidianas. El área enfrente de cada pieza pudo haber sido escenario de intercambio social entre adultos y juegos infantiles.

Los artefactos rescatados del dormitorio de los neofitos, demuestran cómo a menudo nuevos materiales y técnicas se fundían con formas y funciones indígenas. Objetos de metal, cristal y cerámicas importadas representan nuevos tipos de artefactos recibidos por movimiento comercial o contacto. Tales artículos pueden haber jugado un papel importante en el control y la manipulación de la población indígena. La arquitectura misional y alfarería locales representan nuevos tipos de materiales que imitaron modelos importados, pero fueron realizadas de materiales nativos en el sitio. Los textiles son ejemplos de artículos que se producían en el sitio con lana de borregos importados mediante la técnica foránea de tejer en telares. Los cristales y puntas de proyectiles de porcelana representan tipos de artefactos tradicionales que fueron modificados mediante la substitución de materiales locales por materiales importados. Los métodos de tablajería, por lo menos en lo referente a los animales domésticos recién incorporados, fueron totalmente españoles, aunque la cacería y recolección de plantas domésticas comestibles, tales como bellotas y piñones, continuaron en una base esporádica y suplementaria. El proceso de aculturación fue muy complejo. No llegó a ser completo, ni fue un proceso de un solo sentido, pero es representado por una fusión completa de rasgos salinanos y españoles.

\section{EL CUARTEL (1979-1983)}

Como en otras misiones, San Antonio tenía una escolta militar que consistía de un cabo y cinco soldados rasos, cuya función era dar protección a los misioneros franciscanos y neofitos, llevar el correo, y a menudo, servir de una manera informal como instructores en artesanías a los indígenas. La escolta en San Antonio, en realidad casi no desempeñaba actividades militares.

Ya que los alumnos excavaron por completo el conjunto entero, la excavación del cuartel presentó la oportunidad de efectuar preguntas de naturaleza más específica y sofisticada.

Con base en la evidencia documental y arqueologica, se identificaron dos fases distintas de construcción - Componente A (1802) y Componente B (1776)-. La diferencia temporal entre estas fases provee un contraste significativo en el inventario de artefactos de cada fase (figura 5). 

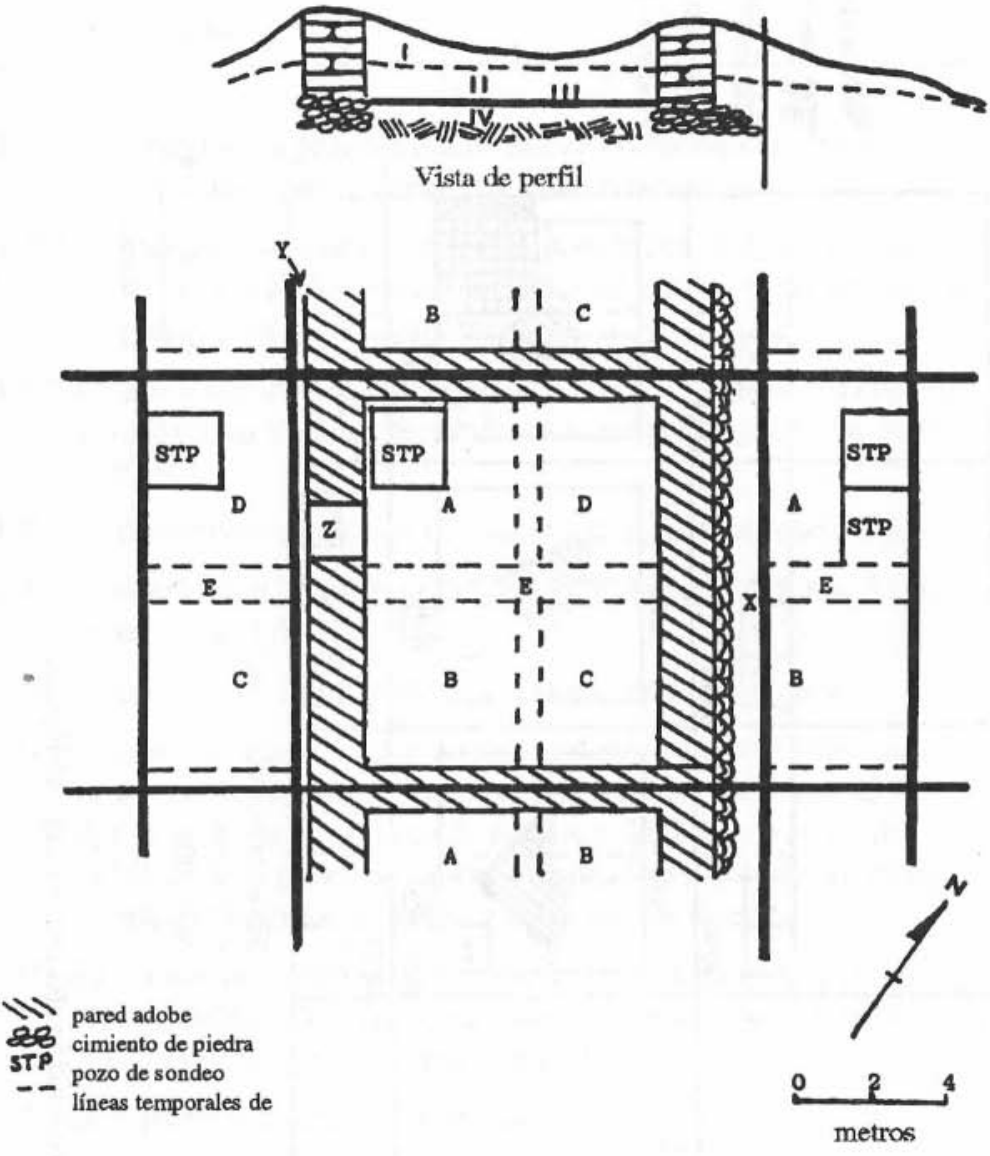

Figura 3. Plano de los dormitorios. 


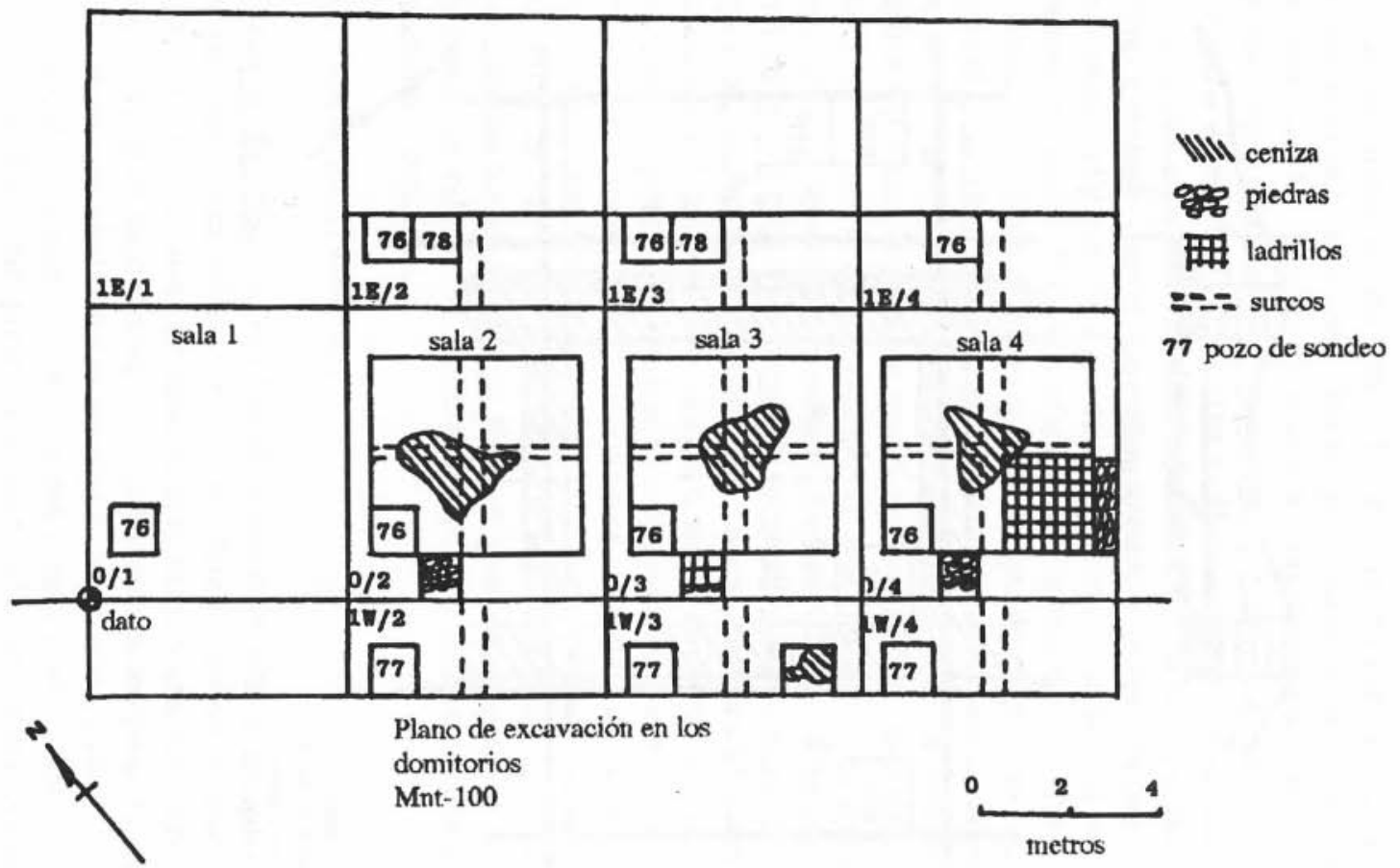

Figura 4. Planos de excavación del dormitorio indígena. 
CUADRO 1. Dormitorio indígena de la misión San Antonio de Padua.

\section{Cronología}

1776 Se construye la primera fila de nueve viviendas contiguas de adobe. Cada vivienda tiene once pies cuadrados.

1780 Se construye un edificio aún más grande con 226 pies de largo y un techo tejado. El edificio se divide en un número desconocido de piezas para familias neofitas.

1805 Se construye un número desconocido de casas de adobe con tejas para familias neofitas. Se empieza la zanja de agua cerca de los edificios.

1806 Se construyen más casas de adobe.con tejados para neófitos.

1809 Se construyen 25 casas de adobe con tejas para neofitos. Se termina la zanja de 1805 .

1810 Se construyen 31 casas de adobe con tejas para neofitos.

$1818 \mathrm{Se}$ construye un corredor detrás del dormitorio para proteger el muro de adobe y para almacenaje de carretas y madera. El corredor se apoya sobre pilares de ladrillo y adobe, y se cubre de ladrillos. Una parte del ala del dormitorio es elevada por cinco hiladas de ladrillos de adobe y se reviste de ladrillos.

1819 Se construye, de adobe y tejados, una nueva ala ( $141 \times 20$ pies). Cuatro quintos del ala sirven como dormitorio para jóvenes (hombres); el resto es una cocina comunal.

1829 Se reparan veinticuatro viviendas neofitas.

1848 Baldosas de dormitorios son llevadas por Mariano Soberanes para usar en su rancho en Los Ojitos.

1878 Bosquejo de Vischer del dormitorio con cobertizo adosado al edificio.

1881 Bosquejos de Ford mostrando parte del dormitorio remanente.

1901 Fotos de Jones mostrando el último cuarto dormitorio. 


\section{CUADRO 2. Categorías de aculturación.}

(a) Objetos que representan nuevos elementos para la cultura, v.g., botellas para vino.

(b) Objetos importados que reemplazan directamente formas prehistóricas, v.g., cuentas de vidrio en vez de concha.

(c) Formas importadas hechas de materiales locales, v.g., baldosas.

(d) Formas importadas, hechas en el sitio utilizando materiales importados y locales, v.g., ropaje con botones de metal.

(e) Formas importadas, hechas en el sitio utilizando materiales y técnicas importadas, v.g., herramientas de hierro.

(f) Formas locales modificadas por la substitución de materiales importados, v.g., puntas de proyectiles de porcelana y cristal.

(g) Formas locales modificadas por la substitución de materiales importados, las cuales utilizan un principio tecnologico distinto para alcanzar la misma finalidad, v.g., ollas de cerámica por ollas de esteatita.

(h) Formas locales con nuevos elementos que cambian el significado del artefacto, v.g. canastas con escudos de armas españolas entretejidos en sus diseños.

(i) Formas locales con los mismos aspectos y significados, pero que utilizan una técnica importada, v.g., cuentas de concha en alambre de hierro.

(j) Formas prehistóricas que continúan sin cambiar, v.g. manos y molcajetes.

El Componente A (1802) está compuesto por una estructura rectangular de cuatro piezas, construidas de ladrillos de adobe sobre cimientos de adoquines fluviales del espesor de un metro, aproximadamente. En 1950, durante la restauración de la misión, se removieron escombros del cuadrángulo con una retroexcavadora al oeste sobre el risco y hacia el arroyo Mission Creek. Así, al dar inicio a las excavaciones, los cimientos del Componente A se encontraban en, o cerca de, la superficie térrea actual. 
La Pieza 1 parece haber sido un arsenal, pues en su área se hallaron pedernales de fusil, balas de mosquete, y un mecanismo llave de chispa Miguelet. La Pieza 2 parece haber sido una sala de estar y un comedor, pues contenía numerosos depósitos de ceniza y también cerámicas de fabricación mexicana, europea, china, y local. La Pieza 3, la mayor del conjunto, fue pavimentada con un suelo de adoquines y enormes cantidades de ceniza, lo que indica la existencia de una cocina. La pequeña Pieza 4, hacia el oeste, tenía una función desconocida.

El Componente B (1776) ha revelado los cimientos de dos piezas, 1 y 2, pasando en ángulo recto por debajo de los cimientos del Componente A. A diferencia del Componente A, el Componente B contenía un alto porcentaje de mayblicas, cerámicas galera, y algunas porcelanas chinas. Por otro lado, el Componente A contenía una gran cantidad de cascos de diseños ingleses y cerámica misión. En el Componente B se utilizó adoquines menores e instalados con más precisión que en el Componente A. Las piezas tienen como 3 metros de ancho y una extensión indeterminada, continuando hacia el norte de nuestra área de excavación.

Existen diferencias significativas en el contenido de ceramica entre los depósitos de las dos fases. El componente B representa un inventario artefactual utilizado durante la época de la fundación original de la misión. Abundaban las mayólicas mexicanas y cerámicas galera. También se registra la presencia de unas piezas de porcelana china. La presencia de cerámicas asiáticas y mexicanas, de producción nacional, reflejan el vigor del imperio comercial español. La importación de cerámicas europeas y la alfarería local todavía no se habían desarrollado. Por otro lado, las ceramicas del Componente A reflejan la disminución del imperio español y la ascensión del comercio marítimo anglosajón a lo largo de la costa californiana. Hay mucha cerámica del tipo perla/crema y del tipo diseño transferido. Hay un descenso en el número de cerámicas mayblica y galera. La presencia de cerámica misión indica el crecimiento de una industria de alfarería local y sencilla que producía cerámicas para cocinar, algo que no se había establecido en la fase anterior entre los indígenas sin tradiciones de alfarería.

Las redes comerciales marítimas en la California costeña parecen haber sido más seguras que las rutas de comercio interinas de las colonias españolas de Tejas, Nuevo México, y Sonora. El arsenal del cuartel contenía abundantes pedregales y balas de fusil, lo que indica acceso relativamente fácil a productos importados, en contraste con otros poblados en el interior de Sonora y Chihuahua, los cuales, debido a la irregularidad de aprovisionamiento, a menudo se veían obligados a defenderse con arcos y flechas. 


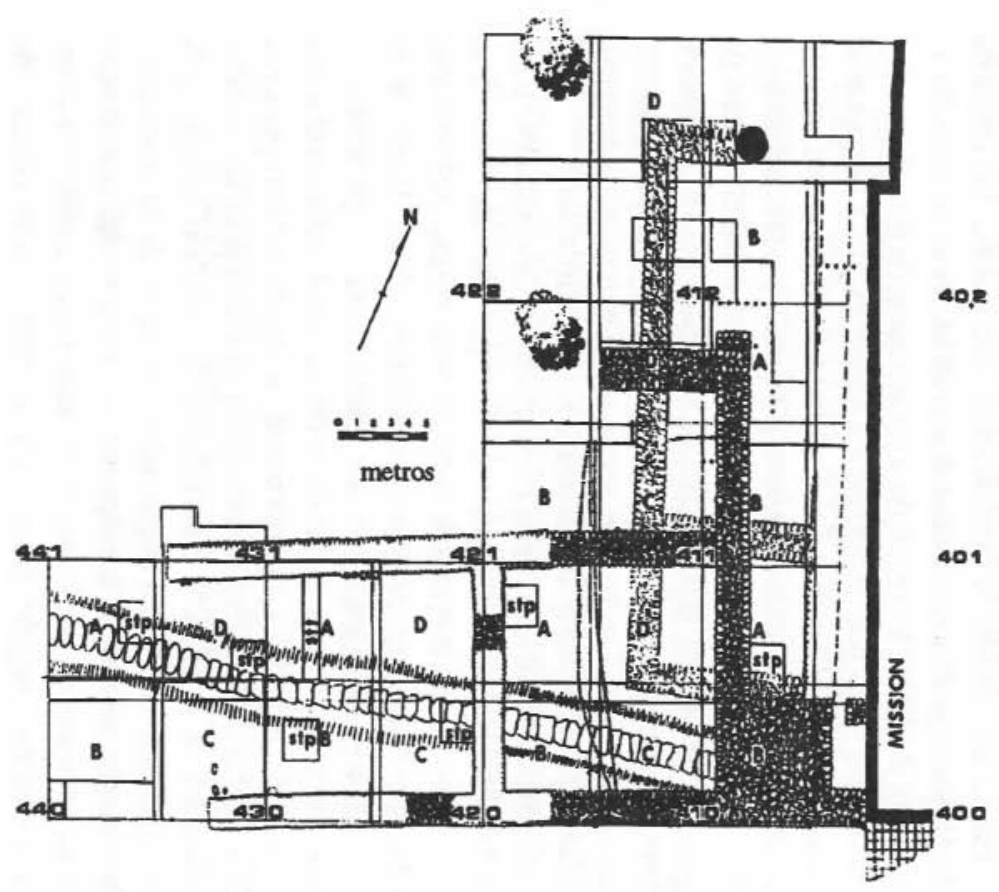

Figura 5. Excavaciones en las barracas de los soldados en la Misión San Antonio de Padua, 1979-1983. 
Como la vivienda de los padres, el cuartel se ubicó adyacente al granero de la misión. Esto indica un mayor acceso y control sobre los recursos más vitales de la misión. Es posible que los soldados hayan cumplido el papel de intermediarios en la redistribución de alimentos en la misión.

Parece haber una relación específica entre la eficiencia subsistencial en aumento y una estructura social misionaria más integrada. El cambio de la cacería y recolección de plantas comestibles a la agricultura y pastoraje fue un paso hacia una mayor eficiencia, pero que requirió inicialmente más esfuerzos para construir acueductos, arar la tierra, montar corrales para animales, etcétera. A menudo los soldados hacían el papel de instructores en las diferentes artesanías necesarias para el desarrollo de la misión, y, así, tenían gran influencia en el aumento de la eficiencia substancial y la integración social.

En los primeros días de la misión, muchos soldados llegaban o como solteros o con esposas indígenas mexicanas, cuyos orígenes se reflejan en las cerámicas nativas mexicanas y un comal encontrado en el Componente B. Después, los soldados tomaban esposas indígenas locales. Las prácticas de remoción de basura parecen más meticulosas en el Componente B. La aculturación de los soldados en las prácticas indígenas locales, a través del matrimonio, daban al Componente A una tendencia hacia prácticas de remoción de basuras más relajadas, al paso que las mujeres se ocupaban cada vez más de los quehaceres domésticos.

Los sistemas hidraulicos tenían mucha importancia en las misiones californianas. Se utilizaron tecnologías españolas y, fundamentalmente, romanas en el medio ambiente seco de California, que es semejante al clima mediterráneo. Las excavaciones por debajo del cuartel revelaron una línea de losas grandes de esquisto que cubrían un acueducto ladrillado cuya base era recubierta de losas adicionales. Esto puede representar el sistema hidráulico de más antigüedad excavado en la California española, remontandose hasta cerca de 1780. El canal puede haber distribuido agua más allá del cuartel, en un riachuelo cercano. Algunos artefactos hallados en el acueducto nos han permitido establecer una fecha más precisa para esta característica del sistema hidráulico.

\section{LA CASA DEL VIÑADERO (1984-1986)}

La excavación completa de la casa del viñadero ha provisto de datos importantes sobre prácticas arquitectónicas y agrícolas de la misión. En 1909 partes de este edificio todavía se encontraban de pie, aunque fotos de esa fecha muestran que el techo y el muro sureño se habían desmoronado. El edificio era cuadrado en general, construido de ladrillos de adobe 
sobre una cimentación de adoquines fluviales. La estructura de una pieza parece haber tenido un desván para el almacenaje de herramientas debajo del techo tejado. De acuerdo con archivos de la misión, el edificio se construy6 en 1895 (figura 6).

El viñadero de la misión parece haber sido un neofito indígena españolizado, a juzgar por la presencia de cuentas y puntas de proyectiles de cristal y concha enterradas en el suelo debajo de escombros de tejas. Por otro lado, el viñadero encontró muchos usos para herramientas europeas (hacha, tijeras, clavos, etcétera) en sus actividades diarias. En cierta ocasión el viñedo estaba circundado de un muro de adobe de seis pies de altura con una corona de tejas de techo. El viñedo contenía parras y árboles fructíferos, y un portón cerrado con llave le proporcionaba seguridad. Quizá una llave grande hallada adentro de la casa del viñadero pudo haber sido diseñada para este portón.

Las misiones de California son conocidas por sus sistemas hidráulicos que fueron derivados de precursores mediterráneos de la antigüedad. El sistema hidráulico de la Misión San Antonio sacaba agua de dos fuentes corriente arriba, la mantenía en una presa común, y la conducía por gravedad a través de las tierras de la misión hasta Jolón, unas seis millas corriente abajo. También había varios pozos artesanos, incluyendo una noria con una cadena sinfín de cubetas que daba en una presa. Este sistema regaba tanto los jardines, pomares y viñedos como varias millas cuadradas de trigales. Una investigación del crecimiento de este sistema en relación con las estadísticas de producción agrícola en los informes anuales y semestrales, revela correlaciones entre estos dos factores. Ademas, el agua fue utilizada en la operación de un molino, complemento importante en la producción agraria de la misión. En estudios futuros se podría utilizar radar tierrapenetrante para trazar el mapa del sistema de irrigación de una manera mas completa.

\section{LA COCINA COMUNAL (1987-1989)}

En el lado oriental del dormitorio de solteros, construido en 1815 , se excavaron las instalaciones de la cocina comunal. Esta investigación da pruebas de que esta ala estaba separada del muro sureño del dormitorio para neofitos casados, por un pasaje donde se almacenaron los ladrillos de los edificios que fueron llevados por el ranchero Mariano Soberanes. Los ladrillos estaban apilados para ser transportados en carretas de bueyes en 1846 , hasta que el robo fue obstaculizado por el gobernador militar de California. 


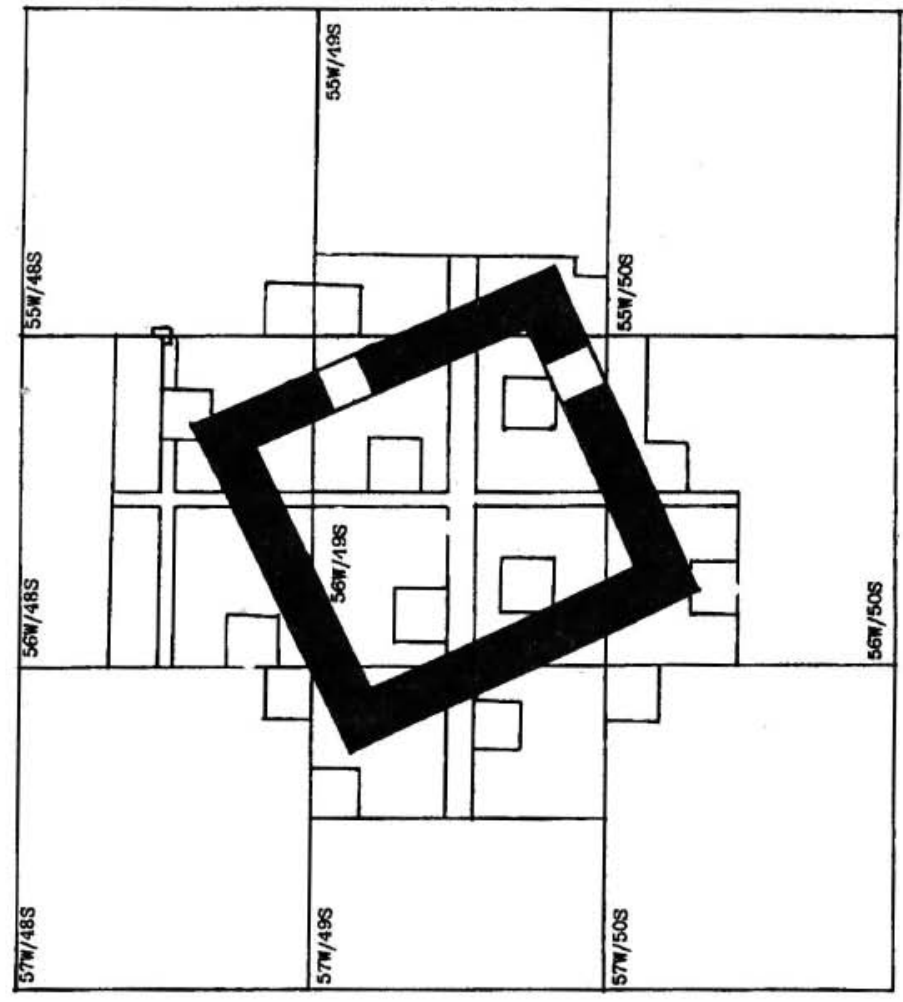

过 
Una capa de ladrillos de adobe forman una plataforma sobre la que se construyó un horno rectangular de adobe. La parte superior del horno estaba cubierta de una capa de ladrillos cocidos y tenía un gran hoyo circular para ollas y una depresion rectangular. Desde el frente norteño, encontramos el final de una pequeña depresión para cocinar, un cajón grande para lumbre que calentaba el hoyo de la olla, y un nicho, posiblemente para la preparación de tortillas. El resto del horno contenía una abertura hacia una chimenea que subía por el lado del muro (figuras 7 y 8 ).

Parece que la dependencia de los neofitos de la misión por alimentos nativos llegó a su apogeo durante los primeros años de la existencia de la misión, cuando la producción de plantas y animales domésticos todavía no se había concretizado. Al momento en que la misión llegó a ser autosuficiente en términos económicos, esta dependencia por alimentos nativos se redujo con rapidez. Debido a la escasez ocasional de los cultivos y preferencias alimenticias de los indígenas, los alimentos nativos nunca se reemplazaron por completo.

La dieta producida por la misión consistía en ambos, alimentos europeos y mesoamericanos domésticos, pero sólo se criaban animales domésticos europeos. Se daba preferencia a los alimentos de origen europeo porque éstos indicaban una categoría superior y a causa de semejanzas climáticas gozaban de mayor fomento oficial. Los alimentos mesoamericanos recibían preferencia cuando las especies europeas no crecían con fuerza. Se alentaba la producción de alimentos indígenas locales solamente cuando otras fuentes de especias dejaban de alimentar a la población de la misión. El cambio a la dependencia en plantas alimenticias y animales domésticos como fuentes mayores de alimentos resultó en una sociedad más homogénea y concentrada. Aunque la variedad alimenticia pudo haber disminuido, hubo cada vez más excedentes de comidas.

\section{EDIFICIO DE TIENDAS (1991-1994)}

El ala de tiendas de la misión, ubicada paralelamente al lado oriental de la iglesia, se construyó en 1815 y, según documentación histórica, contenía talleres de alfarería, herrería, salas para la producción de hilados y tejidos, un deposito de herramientas y una caballeriza. Los cimientos exteriores y contramuros de adoquines fluviales estaban claramente visibles en la superficie del suelo, pero no había información sobre los usos particulares de las diferentes piezas. Esperamos que nuestras excavaciones nos permitan obtener esta información y datos referentes a la tecnología de la misión. 


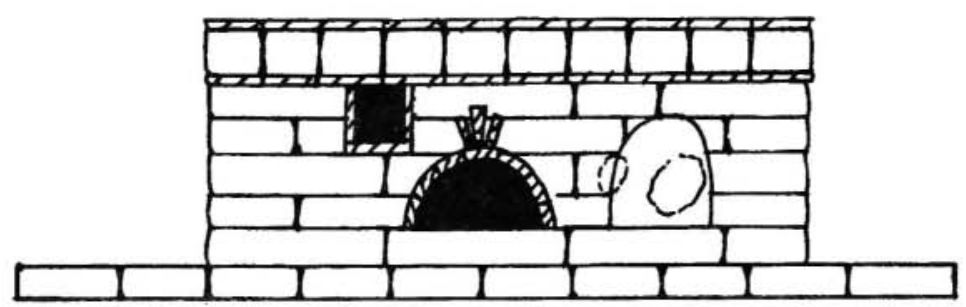

Frente

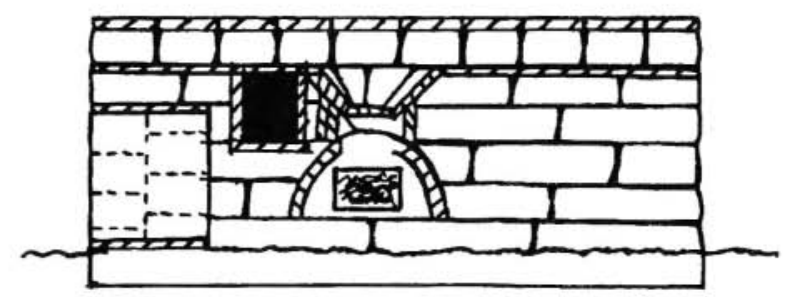

Sección A-A'

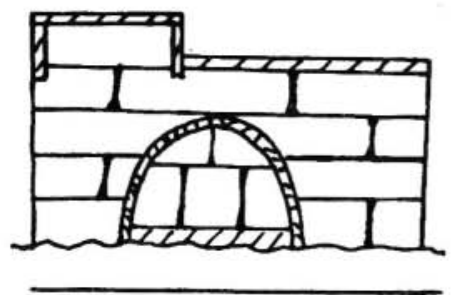

Extremo este

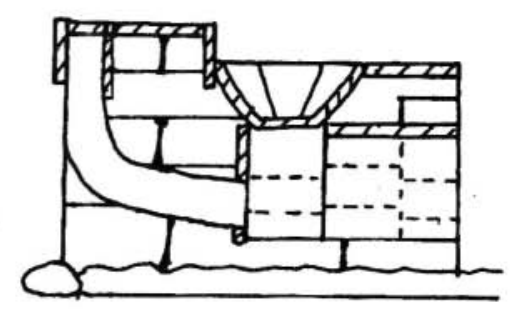

Sección B-B'

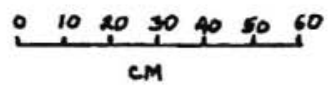

Figura 7. Estufa. 

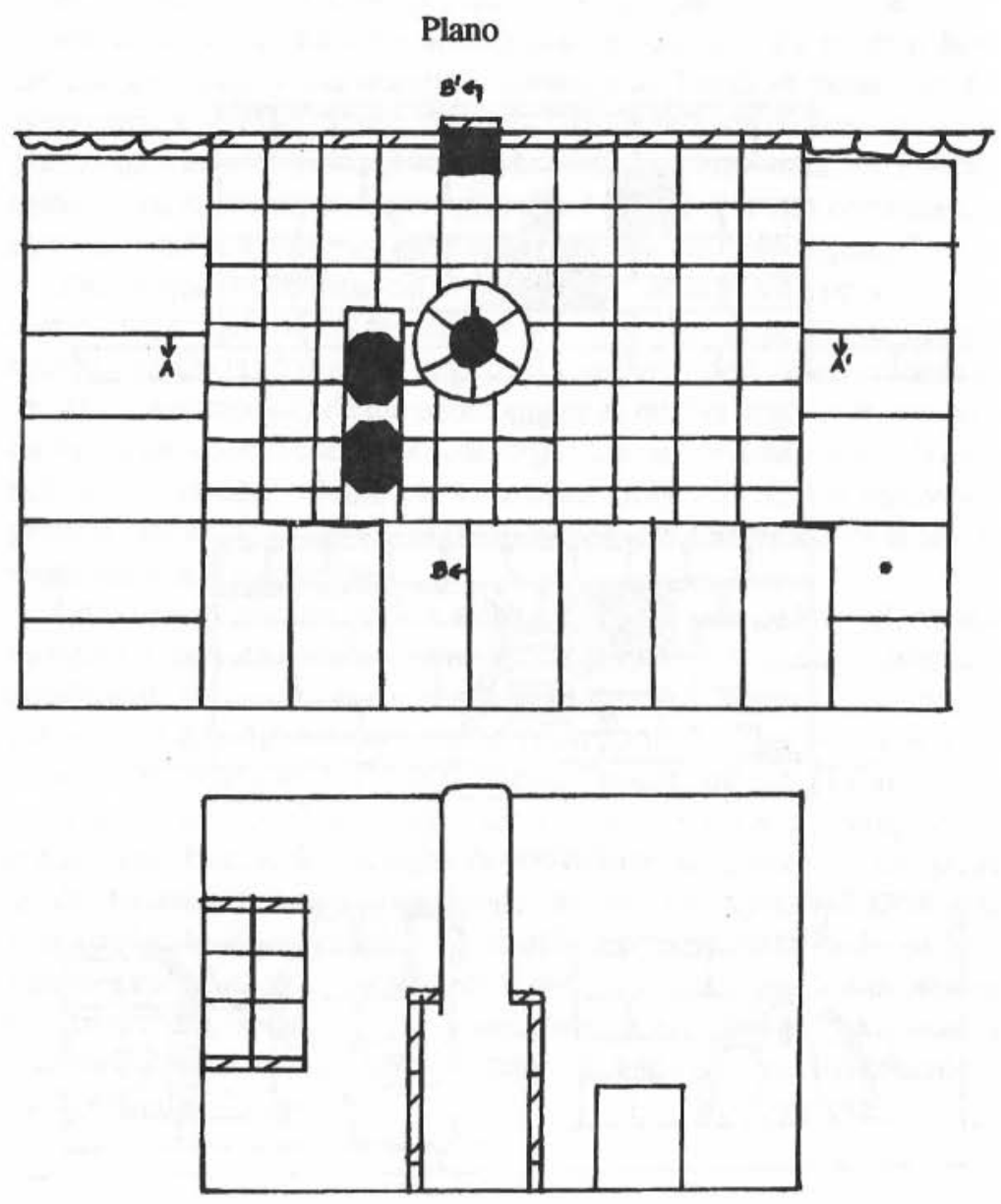

Sección a $30 \mathrm{~cm}$

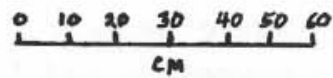

Figura 8. Estufa. 
En la década de 1790, el gobierno español costé los salarios de algunos artesanos maestros que fueron enviados a las misiones califor-nianas bajo contrato, para enseñar artes industriales europeas a los neofitos. Entre ellos se encontraba a Mariano Tapia, maestro alfarero, quien vivió en la Misión San Antonio de 1791 a 1795 y que inició la producción de barro cocido (mission ware) entre los indígenas que no tenían técnicas cerámicas nativas. Esta industria creció al punto de que la Misión San Antonio podía cambiar sus cerámicas de sobreproducción por productos de otras misiones hacia el norte y el sur. No es usual saber tantos detalles, hasta el nombre del alfarero maestro, sobre una artesanía del siglo XVIII de la región fronteriza colonial española.

La cerámica de barro cocido (mission ware) en la Misión San Antonio fue confeccionada mayormente en ruedas giratorias de la tradición europea, con distintos niveles de habilidad reflejando la experiencia de cada alfarero. Se utilizaron ollas y jarros principalmente para la preparación y presentación de comida. La mayoría de estas vajillas tienen superficies calcinadas o teñidas de grasa. Conforme se avance en la investigación esperamos poder determinar cuál de los talleres fue dedicado a la alfarería y también poder precisar detalles de su manufactura.

La producción de lana y tejidos en las misiones californianas se volvió muy importante en la primera parte del siglo XIX. No obstante, batanes, como el de la Misión Santa Inés, eran raros. Las tentativas de industrializar las misiones llegaron demasiado tarde para conseguir el apoyo financiero necesario. Telares típicos de las misiones y otra tecnología similar han sido reconstruidos en la Misión La Purísima. Esperamos utilizar los datos artefactuales para identificar la presencia de talleres de la producción de hilados y tejidos y para precisar los pormenores de su producción.

Por lo general, las herramientas de metal en las misiones eran importadas y reparadas en el sitio. Puesto que los objetos de metal eran relativamente inusuales en el periodo misional, a menudo se substituían por piedra. Con frecuencia, los objetos de metal eran reparados por el herrero, figura de mucha importancia en cada misión, quien también producía clavos, bisagras, cerrojos y otras herramientas esenciales para la albañi-lería. Basado en evidencia arqueológica, en la Misión La Purísima se ha reconstruido una forja española utilizable. Esperamos que nuestras investigaciones nos enseñen más sobre la herrería española.

La Misión San Antonio ostenta una gran colección de herramientas españolas de metal, las que se recuperaron durante la reconstrucción del cuadrángulo en 1948-1952. Aunque se ha perdido su contexto arqueológico, podremos obtener muchos ejemplos útiles del arte del herrero y reconstruir detalles de la producción de estas herramientas. 
Algunas de las herramientas que el herrero de la Misión San Antonio producía o reparaba han sido rescatadas arqueologicamente y en la actualidad se encuentran en exhibición en el museo de la mision. Ellas incluyen: hachas, azuelas, cuñas, serruchos, cuchillos, clavos, herraduras, barras de balanza, ollas, hierros de marcar, cuchillas sencillas, hoces, guadañas, rejas de arado, mayales, ganchos de podar, azadas, palas, tijeras y tijeras de esquilar, cinceles, pestillos, bisagras y herraduras y tenazas.

\section{EL MURO DEL HUERTO (1993-1994)}

En 1825, apenas siete años antes de su secularización, la población de la misión era abumdante y se dedicaba plenamente a proyectos de construccion. En 1816, hacia el nordeste de la iglesia, un huerto grande habfa sido cercado por un muro de adobe. Entre las plantaciones en el huerto se encontraban cerezos y durazneros. Sus semillas carbonizadas fueron recobradas en excavaciones anteriores. En 1825, fuertes aguaceros destruyeron parcialmente el muro del huerto, provocando su reconstruccion. Los arqué́logos descubrieron dos cimientos distintos de adoquines flur- viales en profundidades distintas, una aproximadamente $25 \mathrm{~cm}$ más alta que la otra. El posterior muro de 1825 se construyó paralelo al de 1816, pero no fue colocado directamente sobre los cimientos originales. Una pequeña moneda de plata con el retrato de don Carlos III y una de diez centavos estadounidenses (de 1836) fueron recobradas de estas áreas, junto con evidencia de un campamento al aire libre. Es probable que las monedas representen actividades ocurridas antes de 1821 y después de 1846 . En 1850 , un equipo de topógrafos visito la misión, a lo mejor dejando la moneda de 1836.

\section{CORRAL DE CHIVOS EL MOLINO A FUERZA DE CABALLOS (1996)}

Dos estructuras misteriosas, para las que no hay referencias documentales específicas, fueron las encontradas en las excavaciones a partir de 1996. El primer edificio, que consistía en un área cercada por muros sin techo, de aproximadamente 14.86 por 14.45 metros en sus medidas externas, fue ubicado en una cuesta poco pronunciada. Se edificaron muros espesos de adobe, con una capa de tejas sobre cimientos de adoquines fluviales. El interior del área carecía de artefactos, pero tenía pavimentación adoquinada con cal y subsuelo. Al realizar excavaciones exploratorias, se fijaron las dimensiones de la estructura que correspondió en tamaño a un chivetero 
construido en 1827. No se hallo un sumidero, algo necesario en un terreno inclinado, sin embargo, esta funcion pudo haber sido cumplida por un posible portón ubicado en el punto más bajo del muro occidental.

La segunda estructura presentó problemas más complejos de interpretacion. Con dimensiones externas de 14.38 por 8.88 metros, la estructura consistía en un edificio de adobe con techo tejado sobre un cimiento adoquinado y un patio tangente pavimentado con losas de esquisto, también cerrado por un muro de adobe coronado de tejas de techo. Basado en sus dimensiones y aspectos descubiertos, la estructura construida en 1823 parece haber sido un molino que funcionaba con fuerza de caballos. Los vestigios de una superestructura de adoquines en el centro del patio pudieron haber sido el soporte de las muelas. El edificio adyacente pudo haber sido utilizado como granero. Se encontró una reja de arado apoyada contra el muro interior, y se recupero un candado justo enfrente del portal. También fueron recuperadas dos puntas de proyectil, algunas cuentas de cristal, y muchos clavos cuadrados, lo que indica un alto nivel de sincretismo cultural. Las obras en esta estructura continuarán durante 1997.

\section{RESUMEN}

Las investigaciones descritas arriba ponen de relieve las ventajas obvias de realizar investigaciones arqueologicas en misiones abandonadas y relativamente inexploradas, como son las misiones de la Alta California de San Antonio de Padua y La Purísima; las de San Pedro Mártir, San Fernando Velicat, y San Francisco Borja de Adác en Baja California; y San Francisco Xavier de Viggé-Baundó. Cuanto mejor sea el estado de preservación, más detallados pueden resultar los datos recuperados, y más sofisticadas las investigaciones que se pueden llevar a cabo. En sitios como estos, también se hace claro que hay ventajas, ambas cientificas y logísticas, al realizar investigaciones más a fondo en un largo periodo de tiempo. Todas las misiones compartían ciertas afinidades básicas, pero también pueden ser identificadas por sus diferencias individuales. Estas diferencias pueden existir debido al medio ambiente local, la política de las diferentes órdenes religiosas, el carácter de los residentes indígenas, y muchos otros factores. A través del tiempo, las futuras investigaciones intensivas realizadas en los sitios seleccionados, deberán mostrar estas diferencias.

Y, ¿qué ocurre con los sitios de misiones no escogidos para investigaciones intensivas? Todavia son componentes importantes de los patrimonios de México y Estados Unidos. Merecen igual protección bajo las leyes de ambas naciones. A pesar de tales legislaciones, es claro que ninguno de los dos países posee fondos monetarios para garantizar la 
protección por completo de sus recursos arqueológicos, sin el apoyo y cooperación activos de la comunidad local. Los sitios de las misiones son focos naturales de orgullo comunitario y de cohesión social. Programas educativos suministrados por arqueólogos, maestros, y la sociedad civil en general pueden contribuir mucho a la protección de estos sitios. 


\section{BIBLIOGRAFIA}

BLAKENEY, Karen. 1980. "Timoteo Ware". The Masterkey 54:4:154156. Southwest Museum. Los Ángeles.

HOOVER, Robert L. 1977. "Ethnohistoric Salinan Acculturation". Ethnohistory 4:3:261-268. American Society for Ethnohistory, Tucson.

- 1979. "The Mission San Antonio de Padua in California". Archaeology 32:6:56-58. Archaeological Institute of America, Nueva York.

- 1980. "Agricultural Acculturation at Mission San Antonio". The Masterkey 54:4:142-145. Southwest Museum, Los Ángeles.

- 1982. "A Spanish Aceqaia at Mission San Antonio". The Masterkey 56:2:69-72. Southwest Museum, Los Ángeles.

- 1983. "Ceramic Effigies from Mission San Antonio". The Masterkey 57:1:28-33. Southwest Museum, Los Ángeles (co-authored with Catherine C. Ferguson).

- 1984. "Window on a California Mission". The Masterkey, 58:4:2025. Southwest Museum, Los Ángeles.

- 1985a. "The Archaeology of Spanish Colonial Sites in California". Comparative Studies in the Archaeology of Colonialism. British Archaeological Reports International Series 233, 93-114. Oxford.

- 1985b. Excavations at Mission San Antonio, 1975-1978. UCLA Institute of Archaeology Monograph XXVI, Los Ángeles (coeditado con Julia Costello).

- 1989. "Spanish-Native Interaction and Acculturation in the Alta California Missions". Columbian Consequences (vol.1): Archaeological and Historical Perspectives on the Spanish Borderlands West, 395-406. Smithsonian Institution Press, Washington.

- 1995. "Alguns modelos para arqueologia em Missões Colonials". Revista de Arqueologia, 8:2:321-334. Sao Paulo, Brasil.

WILLIAMS, Jack S. 1981. "A Flintlock Mechanism from Mission San Antonio". The Masterkey 55:1:23-26. Southwest Museum, Los Ángeles. 